\title{
Consumo, Violência e a constituição de identidades na modernidade tardia
}

Marcia Perencin Tondato ${ }^{1}$

\section{Resumo}

O objetivo é discutir a constituição de identidades, do ponto de vista da cultura do consumo, pensada no contexto da sociedade midiatizada em que a violência é matéria-prima essencial tanto para os conteúdos jornalísticos como nas relações estabelecidas no mundo virtual. São problematizadas as imbricações entre a cultura do consumo e uma cultura da violência entendendo que esta intersecção se dá por meio do simbólico, em especial no contexto midiático, como estratégia de mobilização dos indivíduos em prol da manutenção das perspectivas hegemônicas. A discussão desenvolve-se a partir do entendimento do consumo como referente fundamental para conformação de narrativas sobre si e sobre o outro, compondo universos simbólicos repletos de significações. A reflexão se dá com base em um levantamento bibliográfico com foco em consumo, violência e identidade, salientando o cultural do consumo, abarcando a violência simbólica e como isso impacta a constituição de identidades na modernidade tardia. A violência é pensada entendendo cultura do consumo e da violência como esferas refletoras de significados ideológicos, que alimentam e são realimentadas pela mídia como fonte e modeladora de informação e experiências sobre as mais diversas questões.

\section{Palavras-chave}

Comunicação; Consumo; Identidade; Violência. 


\section{Consumption, Violence and the constitution of identities in late modernity}

\section{Marcia Perencin Tondato ${ }^{1}$}

\section{Abstract}

The objective is to discuss identities constitution from the point of view of consumer culture thought in the context of a mediatized society in which violence is an essential material both for journalistic content and in the relationship established in the virtual world. The imbrications between consumption culture and a violence culture are problematized understanding that such intersection occurs by the symbolic, especially on the media context, as a strategy for mobilizing individuals in favor of maintaining hegemonic perspectives. The discussion is developed from the understanding of consumption as a fundamental reference for shaping narratives about oneself and about the other, composing symbolic universes full of meanings. The discussion is based on a bibliographic survey focusing on consumption, violence and identity, highlighting the cultural aspects of consumption, encompassing symbolic violence and how it impacts the constitution of identities in the late modernity. The violence is thought of as understanding consumer culture and violence as reflecting spheres of ideological meanings that feed and are re-fed by media as source and frame of information and experiences on the most diverse issues.

\section{Keywords}

Communication; Consumption; Identity; Violence. 
A base da discussão aqui apresentada é um cenário caracterizado pelo uso dos bens de consumo na especificação das relações sociais, entendido o consumo como uma atividade cultural, a partir do qual significados são atribuídos em um movimento de reflexão e refração entre funcionalidade e simbolismo. Um consumo que não é apenas de sobrevivência, característico das sociedades pré-industriais, ou de distinção, da elite e da burguesia do início da modernidade. Esta reflexão problematiza as imbricações culturais entre uma sociedade do consumo e contextos de expressão de violência simbólica, tomando como pano de fundo a mídia como "textura geral da experiência”, implicando que tudo faz sentido, tudo tem uma consequência comunicacional, especialmente no cenário contemporâneo transpassado pelos mais diversos meios de comunicação, institucionais ou interpessoais (SILVERSTONE, 2005).

Com base em um levantamento bibliográfico de cunho "vertical", ou seja, aprofundando as noções a partir de autores selecionados conforme a hipótese implícita sobre a constituição de identidades - como problematizada por Hall (2006), Woodward (2009), Bauman (2008) e Giddens (2002) - , pretende-se responder a seguinte pergunta: quais são as possíveis intersecções conceituais para se pensar o processo de constituição das identidades do indivíduo inserido na cultura do consumo, assujeitado a uma violência simbólica, naturalizada na sociedade e alentada pela mídia? A discussão se dá segundo o entendimento de que vivemos em uma cultura do consumo, em uma sociedade midiatizada, em que a vida cotidiana transcorre sob uma cultura da violência, vivida nas ruas (e instituições), aprimorada pelos espetáculos (DEBORD, 1997), atribuída à exclusão (BAUDRILLARD, 2007), carregada de estereótipos e preconceitos (BAUMAN, 2008).

O objetivo é avançar nas discussões acerca da constituição de um consumidor, sujeito da pós-modernidade, caracterizado pelo individualismo, mas também por

valores mais reflexivos: a solidariedade (consumos e campanhas de apoio a organizações não governamentais), o novo pacto familiar (famílias flexíveis e assimétricas), os consumos verdes, o discurso do sustentável e defensável, o multiculturalismo, os produtos balanceados, a aceitação da diferença sexual, e um grande etecetera que nos colocaria diante de uma espécie de novo consumidor cidadão [1] (ALONSO, 2006, p. 84).

No âmbito da violência, um aspecto a ser levantado é o "poder" como expressão máxima de dominação, caracterizando relações sociais ou estabelecendo as relações de consumo, fortemente constituídas pelo simbólico. Desse contexto, e de seu imbricamento na trama cultural contemporânea, a mídia é parte essencial como agenciadora e disseminadora de uma complexa dinâmica de trocas negociadas. E é responsável por otimizar a tolerância da base hegemônica, com os indivíduos 
só aceitando o que reconhecem a partir de seus cotidianos. Woodward (2009, p. 14) diz que "a marcação simbólica é o meio pelo qual damos sentido a práticas e a relações sociais, definindo, por exemplo, marcando quem é incluído ou excluído", de um determinado grupo, de uma determinada identidade e os símbolos em questão passam pela mídia.

Quando falamos em mídia, destacamos as relações culturais das representações em trânsito, viabilizando a circulação de significados, dando "sentido à nossa experiência e àquilo que somos" (WOODWARD, 2009, p. 17). Dessa forma, se estabelece uma esfera relacional que potencializa as referências de poder da situação hegemônica primária, perpassadas pelo consumo, constituintes da identidade do sujeito-indivíduo urbano. O poder na esfera nesse processo de formação de identidades diz respeito à eleição arbitrária, de "uma identidade específica como parâmetro em relação ao qual as outras identidades são avaliadas e hierarquizadas” (SILVA, 2009, p. 83).

A violência é tratada aqui como um dos elementos de intersecção na constituição das identidades dos sujeitos urbanos a partir do destaque dado aos seus efeitos como causas, e não consequências, de uma sociedade cujo cotidiano reflete e refrata uma complexidade originária de uma dinâmica social caracterizada tanto pela legitimação como pela resistência (CASTELLS, 2008). Sobre identidade, Silva (2009, p. 81) compreende ser essa, tal como a diferença, "uma relação social, o que significa que sua definição está sujeita a vetores de força, relações de poder”, portanto imposta e constituindo-se objeto de disputa, e não simplesmente definida.

O indivíduo do qual trato, embora sujeito de suas escolhas, está à mercê de relações de poder cada vez mais volatilizadas nas mais diversas esferas da sobrevivência comum. Um indivíduo que não mais está restrito aos círculos familiares e comunitários, mas é parte de um ambiente sociocultural-econômico-político midiatizado, que exige sua participação - ou morte, porque também os excluídos são parte funcional da complexidade, ao servirem de matéria-prima para as estatísticas sociais que alimentam a mídia (TONDATO, 2007).

Penso também a violência para além de definições elaboradas em momentos históricos específicos, mas adentrando o campo da cultura, utilizando significados ali construídos para contestar condições hegemônicas, pois não fazer isso é continuar a trabalhar dentro de uma racionalidade que vê apenas a ordem da natureza. Nos anos mais recentes, mobilizações promovidas em favor de uma diversidade de grupos e causas nos fazem crer que há um consenso sobre a necessidade de tolerância e o respeito à diversidade. Porém, as informações que nos chegam, por diversos canais, em diversos formatos, nos entregam uma sociedade violenta ao difundir acontecimentos que revelam a consolidação de uma condição hegemônica que se perpetua em novas formas de violência, em manifestações imagéticas e discursivas. A percepção é que estamos mais informados, ou até mesmo que nossa compreensão dos acontecimentos tenha sido ampliada, o que não significa que estejamos mais reflexivos no âmbito 
coletivo.

Morin (1990, p. 120) diz que a racionalização pode nos levar a uma compreensão parcial da realidade, e hoje a mediação tecnológica das relações sociais materializa esta racionalização. Do juízo de valor fundado em tradições, estereótipos e preconceitos, passamos à valoração segundo as “curtidas de seguidores”. Da subjetividade históricoideológica passamos à objetividade-tecnológica. A insegurança e o medo são protagonistas dos cotidianos. Hoje nos amedronta ter um vizinho "estrangeiro", imigrante, com o qual não nos relacionamos, embora publiquemos nossos segredos e desejos mais íntimos para o mundo. Contraditório, mas uma realidade na virtualidade que se tornou o mundo social. Trazer para o início dos anos 2020 esta discussão que me acompanha há quase duas décadas, com foco na relação sociedade-violênciamídia, faz sentido na medida em que insiro o consumo nessa tríade como elemento cultural do processo de atribuição de sentidos.

\section{Quando a cultura é um centro desfocado}

Se o consumo "serve para pensar", se é "a própria arena em que a cultura é objeto de lutas que lhe conferem forma” (DOUGLAS; ISHERWOOD, 2004, p. 102103), “consumir significa intercambiar significados culturais e sociais", motivo pelo qual deve primeiro constituir-se como "um sistema de comunicação amplamente compreensível" (TONDATO, 2010).

A relação que constitui identidades-consumo-comunicação-violência aqui desenvolvida toma a cultura como referente, em um sentido mais amplo, "ao caráter simbólico da vida social, aos padrões de significado incorporados às formas simbólicas compartilhadas na interação social” (THOMPSON, 1999, p. 22). Concepção que pode ser complementada com Eagleton (2011, p. 42), para quem "a cultura chega intelectualmente a uma posição de destaque quando passa a ser uma força politicamente relevante”. Dessa perspectiva, então, entendo a cultura como uma produção histórico-política, lembrando ser um conceito majoritariamente considerado com base em uma história da humanidade centralizada no Ocidente, sem consideração aos feitos, fatos e desenvolvimentos ocorridos no Oriente.

Histórico, político e, portanto, ideológico. Para discorrer sobre o ideológico, recorro à Hannah Arendt (apud SOUKI, 1998, p. 57) que diz que a dominação depende não só de um núcleo, mas também de um composto de elementos, que vão desde questões físicas, "de proximidade", até uma dinâmica estrutural. A ideologia, então, permitiria o ocultamento da realidade ao filtrar tais elementos, originados em um centro, que chegam ao "mundo periférico" recriados pelas formas simbólicas, nem sempre refletindo suas origens.

Da mesma forma que a compreensão do que seja cultura foi sendo modificada conforme transformações sociais (com consequências na conceituação de Homem), 
o termo mídia, após ser apropriado de seu cognato inglês, media, denomina tudo o que abrange comunicação tecnologicamente mediada com caráter de acesso público. Nesse sentido, à mídia é outorgada de uma autonomia que otimiza as relações assimétricas de poder, condições da vida social, por acesso diferenciado a recursos e oportunidades, e por mecanismos institucionalizados de produção, transmissão e recepção de formas simbólicas. O engendramento da mídia no tecido social, obviamente, atinge os mecanismos de atribuições de sentidos e compreensão das realidades.

Nesse sentido, as culturas do consumo e da violência seriam esferas refletoras de significados ideológicos, que alimentam e são realimentadas pela mídia que age como fonte e é modeladora de informação e experiências sobre as mais diversas questões, conforme conceito de midiatização elaborado por Hjarvard (2012). Segundo o autor, o desenvolvimento lógico das tecnologias e estratégias industriais dos meios de comunicação de massa - a partir de uma situação histórica específica, a saber, a trajetória institucional mundial da modernidade à pós-modernidade - resultou em uma "condição institucional social autônoma", daquilo que hoje, genericamente e popularmente, denomina-se mídia (HJARVARD, 2012, p. 60-61).

Na mesma direção e, de certa forma, indo além de seu próprio conceito de "mediação" e aproximando-se da "midiatização" de Hjarvard, Martín-Barbero aponta que o lugar de cultura na sociedade muda quando a mediação tecnológica da comunicação deixa de ser meramente instrumental convertendo-se em estrutural. Segundo o autor, "a tecnologia remete hoje não à novidade de uns aparatos, mas sim a novos modos de percepção e de linguagem, a novas sensibilidades e escrituras" (MARTIN-BARBERO, 2014, p. 79). Vivemos, portanto, em uma sociedade midiatizada, com muitos de seus valores emergentes do consumo, esse entendido, repito, como cultura segundo Slater, para quem

\footnotetext{
o conceito de cultura diz respeito a valores que surgem do modo de vida de um povo, que dão a este povo solidariedade e identidade e que julgam com autoridade o que é bom ou mau, real ou falso, não só na arte, mas também na vida cotidiana. [...] Ser um membro de uma cultura ou de um "modo de vida", em contraposição a simplesmente "manter-se vivo", implica o conhecimento dos códigos locais de necessidades e coisas (SLATER, 2002, p. 69 e 131).
}

Pensar a mídia como uma instituição que se estabelece também como fios de uma teia impacta nossa compreensão acerca das práticas cotidianas e das relações sociais, pois, nessa reflexão estabelece-se no consumo entendido como uma atividade social central da contemporaneidade. Isso "não apenas porque a ele dedicamos grande parte de nossos recursos econômicos, temporais e emocionais, mas também porque é nele que se criam e estruturam grande parte de nossas identidades" (ALONSO, 2006, p. 30). 

consumo

Avançando nas relações entre a cultura do consumo e da violência no âmbito da constituição das identidades, reviso algumas noções-chave constituintes da reflexão em curso.

Reveladas como produtos de uma evolução tecno-científico-comunicacional, as mudanças culturais identificadas hegemonicamente como progresso e desenvolvimento, desde o século XIX, resultaram na constituição de uma sociedade de consumo, disseminada como global. Com isso, as percepções de realidades cada vez mais são orientadas por interesses que se compactuam em alianças baseadas nas dinâmicas de uma economia mundial agregadora de ideologias que alimentam a exploração e a dominação.

É a partir da cultura que o mundo adquire sentido, que significados são atribuídos. Uma das bases da organização das sociedades é o consenso sobre "como classificar as coisas" e é "pela construção de sistemas classificatórios que podemos dar sentido ao mundo social e construir significados" (WOODWARD, 2009, p. 41). Nesse aspecto, a sociedade de consumo se estabelece no ambiente do liberalismo, $o$ que coloca a escolha individual no centro da teoria social, com os indivíduos fazendo suas escolhas "exclusivamente como parte da busca da satisfação de suas agendas". Assim, consolidam uma cultura (do consumo), na qual o que consumimos é muito maior do que a mercadoria em si, constituindo-se um símbolo daquilo que queremos transmitir como parte de nossa identidade, mesmo que não intencionalmente.

O consumo, por sua vez, implica na destruição da essência de algo, que, decorrente dessa "destruição", torna-se um signo. Esse poderá ser classificado de várias formas como: de distinção, exclusão, pertencimento, resistência, sujeição. Mas, de todo modo, de identidade. Identidade que na sociedade pós-industrial, tecnologizada e midiatizada se caracteriza cada vez mais pelo individualismo descentrado das tradições de nacionalidade e direcionado às demandas de busca pelo controle do que possa significar ganho nas relações sociais.

A importância da mídia nesse contexto se estabelece no sentido de que seus "conteúdos alimentam e permeiam o tecido das representações sociais, integrando as orientações valorativas e o quadro de referências que são o núcleo mesmo da cultura, direcionando as transformações que aí ocorrem” (MENDONÇA, 2006, p. 35). Apoiando isso, trago ainda Slater (2002) para quem, hoje, estudar os processos comunicacionais implica falar de um consumo que é dominante e que, de certa forma, estrutura as atividades cotidianas, dando-lhes sentido e identidade. 
Se a mídia estabelece parâmetros para as práticas sociais, se o consumo influencia identidades, é porque refletem o que já constitui estas práticas e identidades, num processo de elaboração das necessidades e desejos por meio do simbólico. Daí participar da sociedade midiática e ser consumidor de bens e serviços transformamse em atividades culturais, naturalizando demandas hegemônicas, inserindo o indivíduo-sujeito em uma dinâmica de virtualidades e realidades simbólicas que podem, eventualmente, turvar o estabelecimento de pertencimentos sociais e políticos (TONDATO, 2010, p. 6).

Consumo e mídia estão imbricados, consistindo-se o primeiro em uma atividade diária, essencial, com a qual nos envolvemos não apenas por necessidades materiais e físicas, mas, principalmente, pelas simbólicas, elementos ativos dos conteúdos midiáticos. A atividade de consumir é também "um comportamento cercado por regras que demonstram que nem o comércio nem a força se aplicam a essa relação, que é livre" (DOUGLAS; ISHERWOOD, 2004, p. 104). Partindo do pressuposto de que os bens não são socialmente arbitrários, pois comunicam significados de acordo com a cultura (DOUGLAS; ISHERWOOD, 2004; SLATER, 2008) considero que por meio do consumo as pessoas dizem algo sobre si mesmas, sobre a sua família, sobre o que as tornam singulares, semelhantes ou diferentes das outras. Para Slater (2002, p. 149) as pessoas se integram e se reconhecem ao compartilharem códigos, tangíveis e intangíveis, e participarem de rituais de consumo que constitui dessa maneira "um mundo social inteligível". Ressalte-se aqui a importância do acesso aos códigos intangíveis no processo de compartilhamento.

Ao consumir, não reproduzimos - jamais - apenas nossa existência física; também reproduzimos (sustentamos, desenvolvemos, defendemos, contestamos, imaginamos, rejeitamos) modos de vida específicos, culturalmente significativos. Ao consumirmos rotineiramente, construímos identidades e relações sociais a partir de recursos sociais com os quais nos envolvemos como agentes sociais qualificados (SLATER, 2002, p. 14).

Giddens (2002, p. 79) ressalta que na modernidade tardia os sujeitos são confrontados com uma complexa possibilidade de escolhas de modos de comportamento e de consumo, resultando que as práticas eleitas pelos sujeitos, além de atenderem às suas necessidades utilitárias, "dão forma material a uma narrativa particular da autoidentidade". Vivemos numa ordem pós-tradicional, o que significa dizer que não mais nos orientamos por "sinais estabelecidos pela tradição", isso implica que as identidades fixas não são atribuídas nem indicadas sem ambiguidades (GIDDENS, 2002, p. 81). Nesse sentido, o indivíduo deve "negociar identidades múltiplas e contraditórias à medida que percorre diferentes esferas públicas e privadas, cada qual com seus diferentes papéis, normas" (SLATER, 2002, p. 46).

As soluções antes fixadas pelas autoridades - científica, religiosa, médica são na modernidade tardia ofertadas conforme as particularidades das situações. Também a prevalência da "experiência transmitida pela mídia" (GIDDENS, 2002, p. 
82) tem efeito nas escolhas. Embora o contato real talvez nunca aconteça, por meio do marketing e da propaganda, a pluralidade da vida moderna se traduz diretamente em opções de consumo.

Para Giddens (2002), a autoidentidade abrange esse caráter reflexivo do sujeito em buscar pela identidade que melhor traduza suas crenças e seus objetivos de vida. Ainda que concorde com Giddens, insisto que essa liberdade de escolha não acontece de forma totalmente independente, racional e objetiva como sugere o autor uma vez que ocorre dentro de uma ordem sócio-cultural-econômica-histórica específica. Vivemos sob a dinâmica de um mercado produtor-consumidor que é acelerada e ininterrupta, cujas constantes mudanças devem ser acompanhadas por meio do consumo, de forma que não percamos as posições conquistadas, graças à abertura de uma mobilidade social, agora dependente da posse de bens tangíveis ou intangíveis.

Ademais, tal mobilidade não depende somente da condição financeira, como também decorre da validade da identidade assumida, uma vez que mesmo com a diversidade de possibilidades proporcionadas pela aquisição de bens, também é necessário que o indivíduo seja reconhecido pelos outros como pertencente ou não a determinado grupo. A relação entre os processos sociais de criação e manipulação de símbolos (a cultura da sociedade) e a capacidade de produzir e distribuir bens e serviços (as forças produtivas) têm significado preponderante no estabelecimento das formas culturais em jogo, podendo ser, por vezes, caracterizadas por uma violência simbólica, impondo como normal um conjunto de regras não escritas nem ditas. Assim, é delineada pela primeira vez na história, uma situação em que a mente humana é uma força direta de produção, não apenas um elemento decisivo no sistema produtivo (BOURDIEU, 2001).

\section{Identidade na contemporaneidade}

Quando falamos em identidade estamos necessariamente falando em diferença, resultado de um processo de produção simbólica, discursiva, implicando no estabelecimento de uma relação de poder, pois temos opostos que exigem demarcações sobre "incluir/excluir; demarcar fronteiras; classificar; normalizar" (SILVA, 2009, p. 81).

A história do mundo moderno é uma história de práticas violentas descobrimento, exploração, escravismo, colonialismo. A trajetória do homem ao longo dos últimos séculos, em especial no século XX, criou um ambiente propício para que se considerasse a violência como algo normal, aceitável, inerente à natureza humana, que "não é algo gratuito, pois se insere na lógica da sociedade" (ORTIZ, 2002, p. 37). Giddens (2002) defende que a modernidade pode ser entendida como a expansão de quatro formas institucionais, articuladas e ordenadas: o capitalismo, o industrialismo, a vigilância e o poder militar. A consequência disso é que na 
modernidade vivemos uma sociedade de risco, o que "significa viver com uma atitude calculista em relação às possibilidades de ação, positivas e negativas, com que somos continuamente confrontados, como indivíduos e globalmente em nossa existência social contemporânea" (GIDDENS, 2002, p.33).

Arendt (2001) afirma que a violência e sua glorificação explicam-se pela severa frustração da faculdade de agir no mundo contemporâneo, que tem suas raízes na burocratização da vida pública, na vulnerabilidade dos grandes sistemas e na monopolização do poder, que seca as autênticas fontes criativas. Arendt diz ainda que diante de um revólver, eu entrego os meus bens; diante dos mecanismos simbólicos, eu aceito o contrato hegemônico.

Nesse sentido, consumir promoveria uma catarse, na medida em que ao consumidor é dada a oportunidade de extravasar uma "emoção natural", sem necessidade de expor-se ao perigo ou a críticas por manifestar tal sentimento. Pelo contrário, especialmente em uma sociedade de aparências, em que vale mais o que você posta nas redes sociais do que aquilo que você expressa nas relações sociais.

Outra grande característica da vida social moderna, segundo Giddens, é a acentuada reflexividade das práticas sociais que são "constantemente examinadas e reformuladas à luz de informação renovada sobre estas próprias práticas, alterando assim constitutivamente seu caráter" (GIDDENS, 1991, p.39). Mas antes das práticas, o próprio eu moderno é resultado de um "projeto reflexivo, pelo qual o indivíduo é responsável”; "construído com base no passado, mas visando o futuro"; de um futuro "pensado como cheio de possibilidades, mas não aberto ao livre jogo das contingências" (GIDDENS, 2002, p.74-79). Enfim, reflexivo porque "a realização de um eu autêntico depende da integração das experiências da vida cotidiana com a narrativa do autodesenvolvimento individual”.

Sobre esse aspecto, retomo Arendt (2001) para avançar sobre essa necessidade de planejamento do próprio eu quando a autora diz que com o poder de agir em conjunto diminuído, o homem moderno necessita de implementos para aumentar seu vigor, uma característica individual. E no cenário da presença das tecnologias digitais e consequentes repercussões nos modos de ser e estar na sociedade, isso é algo que tem se mostrado cada vez mais uma realidade se levarmos em consideração as manifestações de ódio, as mobilizações coletivas em prol de atos de violência, entre outras situações de cunho coletivo.

Com base em estudo realizado no início dos anos 2000 sobre a relação entre violência e mídia, tratando da atribuição de sentidos ao que, então, circulava nos meios - em especial na programação jornalística de caráter sensacionalista -, Tondato (2007) conclui que o fato de vivermos uma cultura individualista colabora para a manutenção de uma condição de dominação hegemônica, que é a base de uma programação televisiva que se apropria de valores tais como diversidade, liberdade. A atitude individualista da recepção emergiria, então, na manifestação do entendimento 
de violência televisiva apenas como aquela expressa em atos individuais (deboche, desrespeito), implicando o entendimento de que situações específicas de violência social, institucionalizada (SILBERMAN, 1998), política (MICHAUD, 1989), revolucionária (SOREL, 1992), ou seja, referências à dominação do coletivo não consistiriam elementos de uma cultura de violência, como disposto por Michaud,

como foi a dos pioneiros da fronteira do Oeste americano, e porque não também do Oeste brasileiro, as bandeiras; ou como no caso da mestiça mexicana, onde a violência está ligada à dureza das condições de vida e de sobrevivência, por exemplo, dos meios populares. Nesta categoria incluem-se também as brigas de gangues de rua ou das equipes esportivas (MICHAUD, 1989, p. 25).

Trazendo para o contexto da discussão em curso, Slater (2002, p. 86) afirma que a sociedade contemporânea passou a dominar o indivíduo tanto por meio dos objetos e interesses que se tornaram essenciais para satisfazer necessidades como também para o indivíduo ser e encontrar uma identidade. Nessa mesma linha, esse autor (2002, p. 32) explica que uma cultura "de" consumo caracteriza uma sociedade em que não somente seus valores são organizados pelo consumo, mas de certo modo, dele derivados. Aproximo a noção de uma cultura "de" violência nos termos do uso feito do simbólico pela mídia, promovendo um contexto de poder de "um contra todos", "a forma extrema de violência" (ARENDT, 2001, p. 35), no caso, exercida nos interstícios das relações comunicacionais mobilizadas no âmbito da midiatização da sociedade.

\section{Considerações Finais}

Para o filósofo francês Yves Michaud (1989, p. 16), é possível uma definição de que "a violência contemporânea muda de fisionomia e de escala porque é o produto de sociedades nas quais também mudaram a administração de todos os aspectos da vida social, a tecnologia e os meios de comunicação de massa." Explicitando isso um pouco mais, tomo o pensamento de Stuart Hall (2006) para quem a modernidade e as constantes transformações sociais fizeram emergir nos sujeitos uma sensação de desorientação quanto ao estabelecimento das bases de suas identidades. "Motocontínuo", apresenta-se a esse sujeito a cultura do consumo, configurando-se como um espaço social onde poderá ancorar seu sentimento de desorientação decorrente da emergência de uma percepção de liberdade em relação às determinações identitárias estabelecidas pelo nascimento.

Na contemporaneidade, o consumo é referente fundamental para conformação de narrativas sobre si e sobre o outro, compondo universos simbólicos repletos de significações. Ao consumir, os sujeitos constroem discursos frente à sociedade, discursos esses que dão coesão às suas identidades. Para Slater (2002), através do consumo os sujeitos conectam o campo social à natureza de suas identidades, ou seja, absorvem os sentidos construídos coletivamente e os aplicam à sua esfera individual, 
por meio das práticas cotidianas.

A busca pela consolidação de uma identidade é caracterizada pela incerteza, não tanto pela dúvida sobre "como obter as identidades de sua escolha e tê-las reconhecidas pelas pessoas à sua volta” (BAUMAN, 2008, p. 187), mas pela decisão a respeito de que "identidade escolher e como ficar alerta para que outra escolha possa ser feita em caso de a identidade antes escolhida ser retirada do mercado ou despida de seu poder de sedução" (BAUMAN, 2008, p. 187). Ou seja, não é que o indivíduo siga refém do que recebe da mídia, mas sempre existe o risco de que o que foi escolhido como identidade seja "retirado" do mercado, no sentido de deixar de fazer parte de algo que tenha poder e faça sentido para os outros.

Respondendo sobre as possibilidades para se pensar o processo de constituição das identidades do indivíduo inserido na cultura do consumo, assujeitado a uma violência simbólica, a exposição ao risco de vencimento de nossas escolhas tornase, por assim dizer, o cenário onde ocorre esse processo violento - visto que na modernidade tardia não há identidades fixas e as práticas cotidianas devem ser reflexivas. A violência simbólica é naturalizada na sociedade e alentada pela mídia, refletida nas práticas de consumo, caracterizadas mais pela aparência do que pela essência do exercício de liberdade.

Associando a desestabilização dos sujeitos em relação à constituição de suas identidades decorrente, como dito, das rupturas promovidas pelos descentramentos dos sujeitos (HALL, 2006) à insegurança e receios contemporâneos, a mídia funciona como espelho da sociedade, refletindo e refratando significados por meio de representações que enfatizam comportamentos e padrões que estejam acordo com seus (da mídia) interesses (mercadológicos, ideológicos, etc.). Com isso, optamos por seguir os modelos que nos são oferecidos com fins de constituir uma identidade que se adeque àquilo que desejamos e esteja em conformidade ao que a sociedade espera de nós. Isso porque nos tornamos conscientes de que pertencer e se identificar é algo líquido, que não é garantido para sempre, sendo bastante negociável. Além disso, também nos conscientizamos de que as decisões e ações tomadas diariamente são tão cruciais para pertencer quanto para formar a própria identidade. (BAUMAN, 2005, p. 17).

Mesmo sendo a liberdade um estado desejado, enxergar-se como autor de sua própria história, do seu lugar no mundo, saber-se livre para estabelecer a sua posição como cidadão e sujeito da sociedade em que vive, expõe o indivíduo a uma desestabilização que gera ansiedade e medo devido à imprevisibilidade das consequências dessa "liberdade". Situação que se agrava em uma sociedade em que os meios de comunicação de massa difundem a posse (de bens materiais ou simbólicos) como um aspecto cada vez mais importante para a realização do ser humano que vive o cotidiano do consumo (BAUMAN, 2008, p. 180).

"A identidade, então, costura [...] o sujeito à estrutura" (HALL, 2006, p. 12), 
justificando que os colapsos identitários surjam das mudanças tanto nos sujeitos quanto na estrutura. Crises que podem ser provocadas pela "pluralização de modos de vida" (SLATER, 2002, p.86) e, uma vez constituídas suas "identidades múltiplas e contraditórias", o indivíduo deve "vender" essas identidades aos diferentes "mercados sociais" com vistas a conquistar relacionamentos tanto pessoais como também empregatícios ou de carreira (SLATER, 2002, p. 87).

O indivíduo-sujeito se constitui humano na medida em que se reconhece parte do meio social e histórico em que atua, incorporando valores de autonomia, liberdade e individualidade (ARENDT, 2010). Ainda que as identidades individuais estejam "expostas" a interesses dominantes, a ambientes simbólicos, surgem brechas nesse contexto hegemônico que possibilitam que as identidades "explodam" a partir da multiplicação de referentes (MARTIN-BARBERO, 2006, p. 6o) "desde aqueles com os quais o sujeito se identifica como tal, [...] mas também dos indivíduos, que agora vivem uma integração parcial e precária das múltiplas dimensões que os conformam”. São identidades que somente se completam na relação social, com o outro, conquistando, por assim dizer, seus lugares sociais, o que, na contemporaneidade, embora não em um sentido rígido, ocorre a partir do consumo.

Da mesma forma que o consumo não se constitui uma cultura pelo mercado, a violência não está na sociedade ou essencialmente na mídia. Pelo contrário, os dois fazem parte de uma dinâmica que perpetua exclusões e intolerância, animada pela luta por um poder caracterizado pela supremacia de uma minoria sobre as maiorias. Dinâmica essa que deve ser histórica de modo a ser parte constituinte da individuação para que seja passível de naturalização e aceitação.

\section{Notas}

[1] Tradução livre do original: "valores más reflexivos, recogiendo los tópicos sociales; la solidaridad (consumo, campañas de apoyo a organizaciones no gubernamentales), el nuevo pacto familiar (familias flexibles y asimétricas), los consumos verdes, el discurso de lo sustentable y lo sostenible, el multiculturalismo, los productos equilibrados, la aceptación de la diferencia sexual, y un largo etcétera que nos pondría ante una especie de nuevo consumidor ciudadano".

\section{Referências}

ALONSO, Luis E. La era del consumo. Madrid: Siglo XXI, 2006.

ARENDT, Hannah.A condiçãohumana. 11. ed. rev. Rio de Janeiro: Forense Universitária, 2010.

ARENDT, Hannah. Sobre a violência. 3. ed. Rio de Janeiro: Relume Dumará, 2001. 
BAUDRILLARD, Jean. A sociedade de consumo. Lisboa: Edições 70, 2007.

BAUMAN, Zigmunt. Sociedade individualizada: vidas contadas e histórias vividas. Rio de Janeiro: Zahar, 2008.

BAUMAN, Zigmunt. Identidade. Rio de Janeiro: Zahar, 2005.

BOURDIEU, Pierre. O poder simbólico. 4. ed. Rio de Janeiro: Bertrand Brasil, 2001.

CASTELLS, Manuel. O poder da identidade. 6. ed. São Paulo: Paz e Terra, 2008.

DEBORD, Guy. A sociedade do espetáculo. Rio de Janeiro: Contraponto, 1997.

DOUGLAS, Mary; ISHERWOOD, Baron. O mundo dos bens: para uma antropologia do consumo. Rio de Janeiro: Editora UFRJ, 2004.

EAGLETON, Terry. A ideia de cultura. 2. ed. São Paulo: Editora UNESP, 2011.

GIDDENS, Anthony. Modernidade e identidade. Rio de Janeiro: Zahar, 2002.

GIDDENS, Anthony. As consequências da modernidade. São Paulo: Editora UNESP, 1991.

HALL, Stuart. A identidade cultual na pós-modernidade. Rio de Janeiro: DP\&A, 2006.

HJARVARD, Stig. Midiatização: teorizando a mídia como agente de mudança social e cultural. Matrizes, v.5, n.2, p.53-92, 2012. Disponível em: <https://www.revistas.usp. br/matrizes/article/download/38327/41182>. Acesso em: 15 abr. 2019.

MARTÍN-BARBERO, Jesús. Diversidade em convergência. Matrizes, v.8, n.2, p. 15-33, 2014. Disponível em: <.https://www.revistas.usp.br/matrizes/article/ download/90445/93215/o>. Acesso em: 22 abr. 2019.

MARTIN-BARBERO, Jesús. Tecnicidades, identidades, alteridades: mudanças e opacidades da comunicação no novo século. In: MORAES, Dênis de (org.). Sociedade midiatizada. Rio de Janeiro: Mauad X, 2006, p.51-79.

MENDONÇA, Maria Luiza. Comunicação e cultura: um novo olhar. In: SOUSA, Mauro Wilton de (org.). Recepção mediática e espaço público: novos olhares. São Paulo: Paulinas, 2006, p.27-38.

MICHAUD, Yves. A violência. São Paulo: Ática, 1989.

MORIN, Edgar. Ciência com consciência. Portugal: Publicações Europa-América, 1990.

ORTIZ, Renato. Violência e globalização. Comunicação \& Educação, ano VIII, p.1228, 2002. Disponível: <https://www.revistas.usp.br/comueduc/article/view/37014>. Acesso em: 27 abr. 2019. 
SILBERMAN, Sarah Garcia; LIRA, Luciana Ramos. Medios de comunicación y violencia. México: Instituto Mexicano de Psiquiatría y Fondo de Cultura Económica, 1998.

SILVA, Tomaz T. da. A produção social da identidade e da diferença. In: SILVA, Tomaz T. da (org.). Identidade e diferença: a perspectiva dos Estudos Culturais. 9. ed. Petrópolis: Vozes, 2009, p.73-102.

SILVERSTONE, Roger. Por que estudar a mídia? 2. ed. São Paulo: Loyola, 2002.

SLATER, Don. Cultura do consumo \& modernidade. São Paulo: Nobel, 2002.

SOREL. Georges. Reflexões sobre a violência. São Paulo: Martins Fontes, 1992.

SOUKI, Nadia. Hannah Arendt e a banalidade do mal. Belo Horizonte: UFMG, 1998.

THOMPSON, John B. Ideologia e cultura moderna: teoria social crítica na era dos meios de comunicação de massa. 3. ed. Petrópolis: Vozes, 1999.

TONDATO, Marcia P. Identidades múltiplas: meios de comunicação e a atribuição de sentido no âmbito do consumo. In: TEMER, Ana Carolina R. P. (org.). Mídia, Cidadania e Poder. Goiânia: Facomb/FUNAPE, 2011, p.153-174.

TONDATO, Marcia P. "Uma perspectiva teórica sobre consumo e cidadania na contemporaneidade”. Conexiones - Revista Iberoamericana de Comunicación, v. 2, n. 2, p.5-18, 2010. Disponível em: <https://centresderecerca.uab.cat/oic/content/ volumen-2-numero-2\#PER>. Acesso em: 30 mar. 2021.

TONDATO Marcia P. Cultura e ideologia na atribuição e significados aos produtos televisivos. Revista ALAIC, ano IV, n. 7, p. 124-136, 2007. Disponível em: <http://www. eca.usp.br/associa/alaic/revista/r7/ccientifica_02.pdf>. Acesso em: 17 abr. 2019.

WOODWARD, Kathryn. Identidade e diferença: uma introdução teórica e conceitual. In: SILVA, Tomaz T. da (org.). Identidade e diferença: a perspectiva dos Estudos Culturais. 9. ed. Petrópolis: Vozes, 2009, p.7-72. 